\title{
The Material Culture of Nazi Camps: An Editorial
}

\author{
Gilly Carr $^{1} \cdot$ Marek E. Jasinski $^{2} \cdot$ Claudia Theune $^{3}$
}

Published online: 20 July 2017

(C) Springer Science+Business Media, LLC 2017

The impetus for this special issue of the International Journal of Historical Archaeology lie in the three seasons of excavation that took place at the forced labor camp of Lager Wick in Jersey between 2014 and 2016. The excavation was directed by Gilly Carr, funded by the British Academy in a joint project involving Gilly Carr and Marek E. Jasinski, and also involved the two guest co-editors, who were invited to dig in different years (Marek E. Jasinski in 2014, Claudia Theune in 2015, and paper contributor Ivar Schute in 2016). In addition the three guest editors of this special issue cooperated closely during excavations, surveys, and workshops at the Falstad Camp site in Norway led by Marek E. Jasinski in 2010, 2014, and 2015. This special issue was provoked by the many conversations on both sites regarding, initially, the rules, guidelines, and expectations produced by the many different regions and countries in Europe which dictate what is excavated and kept, and what is redeposited and carefully returned to the ground. This variation clearly had the ability to affect what was retained for study from camps in different countries, with a resulting knock-on effect upon what was published and / or included in exhibitions.

As the excavation of Nazi camps is still a relatively new - but growing - field, excavators from all over Europe clearly have much to learn from and share with each other. It was for this reason that experienced colleagues from across Europe were invited to join the digs in Jersey and Norway. Insight from other camps, their layout,

\author{
Gilly Carr \\ gcc20@hermes.cam.ac.uk \\ Marek E. Jasinski \\ marek.jasinski@ntnu.no \\ Claudia Theune \\ Claudia.theune@univie.ac.at
}

1 Institute of Continuing Education, University of Cambridge, Cambridge, UK

2 Department of Historical Studies, Norwegian University of Science and Technology, Trondheim, Norway

3 Department of Prehistory and Historical Archaeology, Franz-Klein Gasse 1, 1190 Vienna, Austria 
their building structures, their features, and the interpretation of types of material culture commonly found within them, was all vital for the success of the excavation at Lager Wick and Falstad Camp.

Time and again, throughout the seasons of fieldwork, the same questions kept arising - the same issues that seemingly had no answer. For example, how can we know for sure that a particular object dated to the period of the camp and not phases of use before or after? How can we know whether an artifact belonged to a guard or a camp inmate, let alone whether it could speak of the many levels of prisoner hierarchy in a camp? And, perhaps, the further question unrestricted to excavations of Nazi camps regarding object identification.

On-site conversations soon revealed that these were common issues at the excavation of other camps, and it seemed clear that not only did the wisdom and experience of colleagues across Europe need to be distilled into a single written source that one could consult when necessary, but that creative solutions and methodologies carried out at one camp could provide inspiration for dealing with tricky problems in other parts of Europe - and, of course, at sites of internment elsewhere in the world. And thus this special issue was born out of need. Colleagues across Europe were contacted and asked to produce papers. The first round of papers submitted resulted in a collection twice as long as the one you currently see before you. It was heartening to see a deep interest in so many younger scholars, and exciting to read of the range of artifacts surviving and emerging from camps across Europe, and the role that they are playing in preserving or prompting - memories. Some of the papers that did not make the final issue were perhaps too specialized, too broad, or ancillary to the precise topic in hand. In any case, there is certainly potential for future publications in this field.

If this issue is born out of need, it is no coincidence that it is also timely. More than 70 years after the liberation of Nazi camps, the number of survivors is growing fewer and researchers are increasingly turning to material culture and museums to narrate and mediate the experience of the inmates, and to provide evidence of atrocities to counter Holocaust deniers. Archaeology clearly has an important role to play in this respect, as we seek to understand the material culture of the camps. The role and understanding of the spheres and social worlds of materiality and material culture have gone through a very significant theoretical development within social sciences and humanities during the last four decades. Archaeological artifacts and structures are no longer being perceived as fragmentary leftovers, passively carrying incomplete information about past events, but as vital actors of a hybrid coexistence between humans and things and as ever-active agents of individual and social memories. And as the database of material culture grows, archaeologists and museum professionals are facing not only questions of interpretation, but also of mediation, storage, curation, publication, and potential display.

We asked the contributors to this special issue whether the nature of the camps, and the crimes that took place in them, raised the potential value and significance of the items found there to a quasi "sacred" status. What implication did they think this had for the long-term storage of this material? Is every item of value, or should no qualms be felt about throwing away, discarding, or reburying seemingly unimportant things such as fragments of window or bottle glass and lumps of unidentifiable metalwork? And what about the items of indisputably higher significance, such as personal possessions? What should be the long-term trajectory for items which represent the only known representative part of a deceased individual? Should these too be buried 
after recording if they are not to go on display in a museum? Or can attempts be made to track down the family of the original owner? And what can be done with the troublesome problem of looting from camps and the sale of these objects on online forums such as Ebay? Who is buying these items and why?

The guest editors were also concerned about the certainties of interpretation of artifacts (as discussed above). While all of the issues raised have been applied to small finds, we must also consider the impact of these arguments on the remains of camp infrastructure, such as barrack huts, barbed wire, and other aspects of architecture - did they, too, belong to the Nazi-period use of the camp, or the periods before or after - or all of the above? What implication does or should this have on the way we treat such sites today?

Returning to materiality, after an excavation should a museum display always be the ultimate aim of the archaeologist who excavates camps? In these days of digital heritage, what new and exciting opportunities or best practice are emerging for websites, apps, digital mapping, or other methods for reaching a wider audience with the results of excavation?

Museum curators face both similar and unrelated issues when considering the display and interpretation of objects from Nazi camps excavated by archaeologists. Is there pressure to display attention-grabbing headline pieces to the detriment of artifacts illustrative of daily life? Do museum curators have the same aims and motivations as archaeologists? And how much influence do archaeologists have in any future display? Will excavated material always be overshadowed or deemed less important by other kinds of camp objects, such as hand-made arts and crafts, or "memory objects" donated by survivors? Do archaeological artifacts have to compete for display with archival materials like photos, documents, or site models? And where does the display of objects representing the daily life of the overseers, guards, and perpetrators stand? To what extent should such items be shown, and how much of any display should they take up? Certainly objects are not neutral and can be used to narrate politicized versions of the past, but what is the best way to display them? Such issues and more are tackled in this issue and in memorial museums across the world right now.

The authors who responded to our call - and the guest editors themselves - have drawn upon their experience to shed light on these issues and more. Insoluble problems in the field have been turned into features and talking points in museum exhibitions. Conundrums have been solved in the most creative of ways using very detailed "microexcavation" techniques.

The overall impression gained from reading the papers by the authors in this special volume is one of over-abundance of objects, which has greatly facilitated new theories and perspectives. And while a number of authors have highlighted diagnostic, wellpreserved, or especially illuminating items, others have discussed the potential of the more mundane and prosaic objects.

The issue of over-abundance was, perhaps, nowhere more surprising than at Treblinka, where, as Caroline Sturdy Colls and Michael Branthwaite discuss, the presence of material culture contradicted narratives surrounding the complete destruction of the camp by the Nazis. The objects discovered allowed an opportunity to confirm or challenge historical narratives, and make new discoveries about the events that took place at the camp, as well as provide insight into the individual and collective experience of the camp. Sturdy Colls and Branthwaite were also able to explore and then display artistic responses from artifacts found at Treblinka. These have presented 
opportunities for dialogues and revealed new methods of displaying finds together with artistic forms and impressions giving new impulses to visitors.

Taken as a whole, the papers in this special issue grapple with problems presented by a whole range of object types, ranging from the most to the least prosaic. In their paper, Reinhard Bernbeck and Susan Pollock argue that no excavated object is too small or insignificant, if recorded spatially and quantitatively, to reveal stories of suffering but also those of the subversive behavior of camp inhabitants. Their micro-study of the distribution of mundane finds in the forced labor camp at Tempelhof airfield in Berlin reveal the daily "lived space" as opposed to the use of space as conceived by the perpetrators.

Other kinds of small finds discussed in this issue include personalized items such as identity tags, as discussed by Barbara Hausmair. By replacing names with numbers, the National Socialists tried to annihilate their victims' identities. Looking at the tags in more detail, it is striking that many of them are decorated with ornaments, symbols, and inscriptions, such as the places where they have been imprisoned, or their nationality. Through these changes, the tags have become personalized items, which shows a will to maintain a distinct identity in the face of dehumanization. However, focusing only on personalized tags renders invisible the owners of those that were not decorated.

Another form of camp-issued, prisoner-modified material culture is examined by Claudia Theune, who focuses on prisoner clothing, in particular the striped uniform and wooden shoes. Although clothing in particular (and shoes to a lesser extent) are not often the center of archaeological investigation, they do allow us to gain insight into the possibility of different categories of prisoner to act outside the strict rules of the Nazis. Various alterations to the clothes such as patches on the seats of trousers, pockets inserted inside jackets, or prisoner-made shoes show the prisoners' will to possess good clothing and their will to survive. The invisible alterations and hidden pockets give us hints of the small things that the imprisoned did not want the guards to see and hint at survival strategies.

Such creativity and personalization applied by prisoners to objects from the camp is discussed by Johanna Bergqvist Rydén, who analyzes objects brought to Sweden by the women who were rescued from Ravensbrück in the spring of 1945. These objects are presented as intangible expressions of memory and hope for the future; of identity and human integrity; and of resistance and sabotage. These interpretations were gleaned from post-war interviews with prisoners and represented themes vital in helping prisoners cope with the camp regime. These were also part of their strategies to stay alive and to stay human. The very materiality of the objects had a kind of permanence that could give support when intellectual and emotional strength failed.

The many different types of objects from different sorts of camp, and their change in status, value, and meaning over time as they move between contexts, is explored by Gilly Carr. She questions the "sacred" status afforded to objects from high-profile camps such as Auschwitz, asking why (and whether) the same status should not also apply to identical objects from lesser known camps. This has repercussions on the postexcavation treatment of such objects from all camps. Following discussions of status and value, she combines the concepts of the artifact biography and itinerary to explore the changing meaning and value of material culture from Nazi camps over time. She also proposes a categorization of objects from Nazi camps, depending on owner, which place the inmate, their identity, and their body at the heart of analysis. 
Within our categorization of objects from camps we must include the very fabric of camp architecture itself. Like artifacts, buildings also have their biographies and their status as elements of memorial landscapes which can change over time. Paul Mitchell examines this perspective based on his analyses of the buildings still present at the site of the Mauthausen-Gusen concentration camps in Austria. One of the key issues in discussions of the Nazi terror sites is the question of their authenticity. This is also the case for the present day Mauthausen-Gusen complex, which had been created by selective preservation of some buildings and demolition of others. Archaeological analysis of these buildings has revealed important and previously unknown details crucial for understanding their function. Some of the buildings have been adapted to the needs of the present day memorial site, such as exhibition areas, and the issue of their authenticity has become even more complicated.

Maria Theresia Starzmann also focuses on the issue of demolition and erasure of buildings that took place at Nazi camps, examining (along with Bernbeck and Pollock as mentioned above) the site of the camps at Tempelhof in Berlin. Here, a nineteenthcentury military prison was turned into an early concentration camp in 1934. In 1936, Tempelhof became a major airfield with productions plants for the Luftwaffe and for German air defense with associated forced labor camps. Immediately after the war the area became an American air base and, later, a major European international airport. Such processes of destruction created absences in records and archaeological palimpsests within material evidence and within our knowledge of Nazi oppressions and crimes. Each of the new phases of use erased remnants of the former landscape, but only to a certain degree. Sparse archaeological evidence uncovered during excavations showed what was left but also hinted at what was absent.

Moving from the site of the camp to the museum or memorial center, the archaeologist is still involved - or should be, argues Ivar Schute. Writing from the Netherlands, where many of the camps have been forgotten with apparently nothing surviving, Schute shows the potential of archaeology (using the example of the camps at Ybenheer and Westerbork) to raise awareness about the Holocaust. However, he identifies tensions between archaeologists and memorial centers, where the former are needed by memorial centers to generate data for them to display, but which have a tendency to build museum buildings and memorials on top of archaeological sites, thus obstructing access to the archaeological record. Further, some memorial centers (such as at Sobibor) have then cut archaeologists out of the picture, creating problems for further research. Schute argues that when archaeologists are contracted to work for memorial centers, they should be seen as joint partners in the relationship.

Good relations between archaeologists and the museums with which they work are vital, for the work of archaeologists does and should not finish on site. In their paper on Hartheim, Simone Loistl and Florian Schwanninger present their findings from an institution where ca. 30,000 people were killed as part of the Nazi euthanasia program. The huge amount of finds recovered during excavations now play a major role in education activities. The authors describe the importance of using finds for this educational work. Young people learn to tell the stories of the objects from the perspective of the items themselves, and thereby learn not just about the owners (the victims), but also about the Nazi terror in Hartheim.

The value of excavated objects in museum display was also mused upon by Marek E. Jasinski. In common with many authors, he has found problems in dating objects 
from camps which have multiple periods of pre- and post-war use. However, given the central interest of memorial centers, museums, and the public on the war-time period of use, Jasinski suggests a way of using material culture to force through difficult or neglected narratives of the past relating to shameful post-war episodes, such as the reuse of Nazi camps for imprisoning collaborators. By drawing upon theoretical models of materiality and material culture, he discusses the current role of authentic material remains in the formation of social memories. This use of materiality often influences memorial sites and their educational purposes, which in turn affects social perceptions of a painful past among the public. Jasinski thus proposes a future use for the archaeological artifacts recovered during his research at Falstad Camp site in central Norway. These evocative and emotive objects could be used in future exhibitions at the Falstad Memorial and Human Rights Centre, as significant actants for interactions with visitors to illuminate some still-problematic and neglected aspects of Norwegian WWII history and the early post-war period. Thus, the material culture of Nazi camps has a powerful role to play in narrating neglected pasts and forcing a coming-to-terms with periods about which people still find difficult to discuss.

The case has clearly been made for the excavation and analysis of material culture from Nazi camps, and the creative and valuable use to which they can subsequently be put. But with a plethora of objects emerging from across Europe, it is imperative that the maximum amount of information can be gathered from them. The production of European guidelines for best practice in the excavation of Nazi camps is probably a topic best addressed by a round table session at a future international conference. This observation comes with caveats: it is highly likely that no such guidelines can be formulated given that every site is different and has its own practical requirements. However, exchange of experiences, ideas, and solutions from different sites will always be of significant value. While it might be useful to fall back on a document which provides advice that can be invoked in discussions with landowners, planners, environmental officers, local heritage organizations, memorial centers, regional authorities, or any bodies or persons who might have a view that runs contrary to the interests of archaeologists or the archaeological record, at the end of the day each archaeologist must make his/her own decisions regarding which artifacts to retain and which to redeposit. It seems clear, however, that any position which advocates removing objects from sites with the express intention of destruction or discard is something which cannot be supported archaeologically.

The guest editors of this volume are of the opinion, however, that while uniform European guidelines per se are difficult, impractical, or debatably even inadvisable to implement, we wholeheartedly support the creation of a European database of object types found at camps. This would not only facilitate the identification of "mystery" objects, or items too corroded, rusty, or fragmentary to identify, but it would help to build typologies of objects and contribute significantly to our knowledge of Nazi camps as entangled networks of oppression and genocide. The dating of plastic items such as toothbrushes and non-specific buttons is particularly difficult, and such typologies, especially of brands, could only be beneficial in that regard. Such a database would also allow archaeologists to get a sense of how unique or standard their sites were, and would help the identification of the function or use of the building they are excavating. Such a database would also benefit from the addition of items of material culture currently in Holocaust / memorial museums and in archives, as well as objects currently 
being newly excavated by archaeologists. There is clearly a large "back catalogue" in need of digitization and much potential to be found in the digitization and placing online of data currently confined to printed media. There is also no reason why such a digital database could not include camp buildings, rooms, or barrack types / uses as identified from foundations or aerial photographs. This would enable insights into the range of camp layouts and typologies based on architecture. Indeed, there is potential for further discussion on this very subject, but we will leave this for a future issue of the International Journal of Historical Archaeology. 